\title{
A (NOVA) POLÍTICA MIGRATÓRIA BRASILEIRA: AVANÇOS E DESAFIOS NO CONTEXTO DA CRISE HUMANITÁRIA VENEZUELANA
}

\author{
THE (NEW) BRAZILIAN MIGRATION POLICY: ADVANCEMENTS AND \\ CHALLENGES IN THE CONTEXT OF THE HUMANITARIAN CRISIS IN \\ VENEZUELA
}

DOI: http://dx.doi.org/10.5380/cg.v9i1.72550

Thiago Augusto Lima Alves ${ }^{1}$

\begin{abstract}
Resumo
A crise humanitária vivenciada na Venezuela tem causado o aumento do número de solicitações de refúgio no Brasil. Nesse âmbito, este artigo problematiza a construção histórica pertinente às legislações nacionais sobre refúgio, à luz dos tratados internacionais de Direitos Humanos dos Refugiados, e propõe uma reflexão sobre os desafios enfrentados pelo Brasil quando da recepção dos refugiados venezuelanos que chegam ao País. Assim, o objetivo geral do trabalho é analisar a construção histórica das atuais legislações nacionais sobre direitos desse grupo de pessoas e propor uma reflexão a respeito de alguns desafios enfrentados para a aplicação das normativas no contexto atual dos refugiados venezuelanos que chegam ao Brasil. A incursão metodológica que possibilita a realização desta investigação é direcionada por abordagens de pesquisa qualitativa e por método indutivo. O procedimento metodológico é bibliográfico e documental. Como considerações finais, verifica-se que, apesar de haver uma política migratória de defesa aos direitos humanos dos refugiados, algumas adversidades ainda estão presentes, como a efetivação das legislações, o que impacta diretamente a vida dessas pessoas.
\end{abstract}

Palavras-Chave: Direitos Humanos; Refugiados Venezuelanos; Venezuela; Brasil.

\begin{abstract}
The humanitarian crisis in Venezuela has caused an increase in the number of asylum applications in Brazil. In light of this context, this article calls into question the historical construction of national refugee laws based on the international treaties on Human Rights and Refugee Protection, and proposes a reflection about the challenges faced by Brazil with regards to sheltering the Venezuelan nationals who seek refuge in the country. Thus, the general goal of this work is to analyze the historical construction of the current national legislation about the rights of asylum seekers and propose a reflection about some of the challenges faced when implementing directives in the current context of Venezuelan refugees in Brazil. The methodological incursion which enables the accomplishment of this investigation is guided by a qualitative approach and the inductive method. The methodological procedure is bibliographic and documental. As concluding remarks, it is possible to verify that, despite there being migratory policy for the defense of refugees' human rights, some adversities are also present, namely the implementation of legislation, which directly impacts the lives of these people.
\end{abstract}

Keywords: Human rights; Venezuelan refugees; Venezuela; Brazil.

\footnotetext{
${ }^{1}$ Mestrando em Relações Internacionais pelo Programa de Pós-Graduação em Relações Internacionais da Universidade Federal da Integração Latino-Americana (PPGRI/UNILA). Especialista em Direito Constitucional pela Universidade Regional do Cariri (URCA) em 2019. Graduado em Direito pela Universidade de Fortaleza (UNIFOR) em 2017. E-mail: thiagolimaalves.adv@gmail.com. ORCID: https://orcid.org/oooo0o01-6354-3107.
} 


\section{INTRODUÇÃO}

A história do Brasil é marcada por fluxos migratórios. Desde o início do processo de constituição do Estado-nação, migrantes chegavam de outros países, de forma voluntária ou não. Esses estrangeiros, assim como a população autóctone, trabalharam na construção do País. Ao final do século XIX e início do século XX, o Brasil recebeu importantes fluxos migratórios, como os de japoneses que fugiam da crise econômica; de europeus que escapavam das guerras e crises que assolaram sua região; e, mais tarde, de chilenos que buscavam refúgio da ditadura militar. Durante o século XXI, diversos grupos de refugiados procuraram o Brasil para fugir de instabilidades políticas (angolanos, congoleses, sírios) e econômicas (bolivianos, senegaleses, bengaleses) e de desastres naturais (haitianos).

No decorrer do século XX, devido ao grande número de refugiados gerados pela Segunda Guerra Mundial, a internacionalização dos direitos inerentes aos seres humanos e a reflexão/revisão sobre o tema dos refugiados originaram acordos internacionais direcionados para esse grupo de pessoas. O Brasil foi o primeiro país da América do Sul a ratificar, no ano de 1960, a Convenção Internacional de 1951, relativa ao Estatuto do Refugiado. Em razão das limitações, temporais e geográficas, evidenciadas na Convenção Internacional de 1951, foi estabelecido, em 1967, o Protocolo sobre o Estatuto dos Refugiados, que propositava a ampliação do alcance da definição do termo. Tal documento foi assinado pelo Brasil no ano de 1972. Posteriormente, o País assinou a Declaração de Cartagena de 1984, um documento regional que influenciou a associação da questão do refúgio à temática dos direitos humanos e ao direito humanitário na América Latina.

Em agosto de 1980, foi criada a Lei n ${ }^{0} 6.815$ (Estatuto do Estrangeiro) e, na década seguinte, foi estabelecida uma legislação para os refugiados, a Lei no 9.474, de julho de 1997 (Estatuto dos Refugiados), alinhada à Convenção de Genebra de 1951, ao Protocolo Facultativo de 1967 e à Declaração de Cartagena de 1984. Em maio de 2017, foi sancionada a Lei no 13.445 (Lei de Migração), que revogou a Lei ${ }^{0}$ 6.815/80. A nova lei, imposta pelo Estatuto do Estrangeiro, concebe a migração como um direito do ser humano e apresenta o desafio de superar a ideologia que considerava o estrangeiro como uma ameaça à segurança nacional.

O relatório World Migration Report 2020, publicado pela Organização Internacional para as Migrações (OIM), estimou 272 milhões de migrantes internacionais no mundo em 2019, o que corresponde a 3,5\% da população mundial. Ainda de acordo com o documento, 41 milhões de pessoas estão internamente deslocadas e outras quase 26 milhões são refugiadas. Já o Alto Comissariado das Nações Unidas para Refugiados - ACNUR (2020) divulgou que existem 41,3 milhões de deslocados internos, 25,9 milhões de refugiados e 3,5 milhões de solicitantes de refúgio. O ACNUR concluiu ainda que o número de refugiados cresceu mais de 50\% nos últimos 10 anos e que mais da metade são crianças (as quais representam $52 \%$ da população refugiada). O documento 
da Agência da ONU para Refugiados revelou que 57\% dos refugiados do mundo são da Síria, do Afeganistão e do Sudão do Sul; os três países que mais acolhem são Turquia, Paquistão e Uganda.

Atualmente, a Venezuela passa por uma crise humanitária que tem causado efeitos no Brasil. De acordo com o ACNUR (2020), a partir de 2014, mais de 4,5 milhões de venezuelanos já saíram do país, o que torna essa uma das mais recentes e maiores crises de deslocamento forçado na Venezuela e no mundo. Existem, conforme dados do ACNUR (2020), mais de 650 mil solicitantes de refúgio e cerca de 2 milhões vivendo sob outras formas legais de estadias nas Américas.

Assim, o objetivo geral do trabalho é analisar a construção histórica das atuais legislações nacionais sobre direitos dos refugiados e propor uma reflexão sobre alguns desafios enfrentados para a aplicação desses direitos no contexto atual dos refugiados venezuelanos que chegam ao Brasil. Especificamente, o trabalho também pretende explorar as variadas faces do refúgio venezuelano, as questões sociais que rondam o tema, bem como a política pública de acolhimento proposta pelo Brasil, a exemplo da Operação Acolhida.

É importante evidenciar a distinção dos conceitos (migrantes, refugiados e solicitantes de refúgio) para que os dados apresentados no decorrer da pesquisa sejam adequadamente analisados. Os migrantes são pessoas que se deslocam espontaneamente em busca de melhores condições de vida e podem optar por retornar para seu país de origem, pois continuam recebendo proteção estatal. Já os refugiados - população estudada nesta pesquisa -, de acordo com a definição do ACNUR, são aqueles que estão fora de seu país de origem devido a fundados temores de perseguição por motivo de raça, religião, nacionalidade, pertencimento a um determinado grupo social ou opinião política, como também devido à violência generalizada, grave violação dos direitos humanos e conflitos internos; não podem ou não querem, portanto, voltar a seu país de origem porque não contam com proteção estatal. Os solicitantes de refúgio são os que solicitaram às autoridades competentes reconhecimento como refugiados em um outro país, mas que ainda não tiveram seu pedido avaliado definitivamente pelos sistemas nacionais de proteção e refúgio.

A incursão metodológica que possibilita a realização desta investigação é direcionada por abordagens de pesquisa qualitativa, pois apresenta o intuito de aprofundar os entendimentos referentes à construção da legislação nacional sobre refugiados, bem como de compreender o processo internacional do fluxo de refugiados venezuelanos que chegam ao Brasil. O método indutivo também é usado, já que se parte de uma hipótese e o propósito é o de confirmá-la ou de refutá-la, para que, por meio da indução, chegue-se a conclusões que são apenas prováveis. $\mathrm{O}$ procedimento metodológico é bibliográfico e documental, uma vez que é realizado a partir do levantamento de referências teóricas e documentos oficiais já analisados e publicados. A pesquisa é de natureza básica, pois objetiva gerar novos conhecimentos que serão úteis para o avanço das discussões sobre o tema. A busca por esses dados e informações foi estabelecida a partir, principalmente, dos últimos anais do Congresso Brasileiro de Direito Internacional, do Boletim da Sociedade Brasileira de Direito Internacional, de repositórios institucionais, das bases/plataformas 
de conteúdo científico (Portal de Periódicos da CAPES, SCOPUS e SCIELO), como também por meio de órgãos governamentais nacionais, como o CONARE e a Polícia Federal, e internacionais, como o ACNUR e a OIM.

\section{VENEZUELA: CRISE HUMANITÁRIA}

A Venezuela é um país da América do Sul que faz fronteira com o Brasil, a Colômbia e a Guiana. A capital é Caracas e a população ultrapassa 32 milhões de habitantes. Em meio a processos de crises econômicas que atingiram a região na segunda metade do século passado, muitas pessoas procuravam outros países para recomeçarem suas vidas, mas, nos anos 1960, houve uma redução da imigração internacional e, em 1950, os estrangeiros eram 4,1\% da população total da Venezuela. Já em 1971, representavam 5,5\% e 7,4\% em 1980. Na década de 1990, totalizavam 5,7\% dos imigrantes e, destes, 70\% eram oriundos da América Latina e do Caribe, em especial da Colômbia, representando $51,7 \%$ do total de estrangeiros, seguidos de peruanos, equatorianos, bolivianos, dominicanos, guianenses e haitianos (SARMENTO, 2000, p. 30).

Essa realidade, no entanto, mudou e, segundo o ACNUR (2020) informa em seus relatórios, a partir de 2014, mais de 4,5 milhões de venezuelanos já saíram do país, fato que significou uma das mais recentes e maiores crises de deslocamento forçado no mundo. A crise que acontece na Venezuela é complexa, pois envolve outros países, petróleo e luta pela liderança do país, que atualmente encontra-se sob o comando de Nicolás Maduro.

A região passou por muitos períodos de instabilidade política/econômica/social, mas durante o mandato de Hugo Chávez, com investimentos na área social (sustentados pela rede petroleira) que foram fundamentais para a legitimação do regime junto às camadas populares, foi possível garantir as condições de governabilidade (OLIVEIRA, 2011). Porém, após a morte de Chávez em 2013 - o político comandava o país desde o ano de 1999 -, o então vice-presidente Nicolás Maduro chegou à liderança do país em caráter interino e convocou eleições, vencendo Henrique Caprilles, para um mandato de seis anos.

Na época de Chávez, a aprovação do governo do qual Maduro fazia parte beirava os 64\%. Maduro, contudo, herdou uma economia em frangalhos ocasionada principalmente pela queda do petróleo - o país detém a maior reserva de petróleo do mundo e tem a economia totalmente atrelada à venda dessa mercadoria, cuja receita financiava os programas e serviços sociais. Dessa forma, a população venezuelana começou a sofrer com a falta de alimentos e de remédios e com os altos índices de desemprego e violência, situação que desencadeou uma crise de caráter humanitário, quando houve a saída maciça das pessoas para outros países em busca de melhores condições de vida. 
A mudança de presidente ocorrida no Brasil em 2018 e, consequentemente, a mudança da política externa adotada alteraram as relações diplomáticas estabelecidas com o país andino, o que dificultou o processo migratório. Ainda assim, Brasil, Colômbia, Equador, Peru, Chile e Argentina têm recepcionado muitos venezuelanos (ACNUR, 2020). Souza e Silveira (2018, p. 120) explicam que "desde 2014 a Venezuela enfrenta uma complexa crise política e econômica, que tem incentivado os venezuelanos a migrarem para países vizinhos, por diferentes motivos e origens: geográficas, sociais, culturais, entre outras”. É importante ressaltar que o Brasil não é o país que mais recebe refugiados venezuelanos. A Colômbia tem mais de 1,1 milhão de refugiados venezuelanos, seguida pelo Peru, com 506 mil; Chile, com 288 mil; Equador, com 221 mil; Argentina, com 130 mil; e, por último o Brasil, com 96 mil refugiados, de acordo com o ACNUR (2020).

A principal rota de entrada dos refugiados venezuelanos no Brasil é pelo município de Pacaraima, no estado de Roraima. A escolha desses indivíduos pelo País pode ser associada à posição geográfica, haja vista que a emigração fronteiriça é uma possibilidade real de ascensão social para o grande número de migrantes que ali vivem e, também, às condições de proximidade e facilidade de acesso via terrestre (RODRIGUES, 2006).

Abdelmalek Sayad (1979, p. 54) entende que o "imigrante é essencialmente uma força de trabalho, e uma força de trabalho provisória, temporária, em trânsito”. No caso dos refugiados venezuelanos, no entanto, não é apenas o trabalho que os faz sair da Venezuela. Emma Haddad explica a diferença entre esse imigrante que busca emprego - sendo essa a principal e única razão para sair de seu país (Sayad, 1979) - e os refugiados:

\begin{abstract}
Outros estrangeiros, como migrantes e imigrantes, podem, é claro, representar um desafio à identidade ou composição étnica de uma comunidade. No entanto, seu movimento transnacional tem sido uma das opções e eles permanecem enraizados na relação estado-cidadão "normal". A refugiada, por outro lado, não teve escolha em deixar seu país de origem. Ela foi forçada a sair da comunidade política doméstica de seu estado de origem e chega às fronteiras de um estado anfitrião solicitando entrada (HADDAD, 2008, p. 7, tradução nossa²).
\end{abstract}

Nesse caso, a partir do momento em que fogem da violência sofrida no país de origem necessitando, assim, que o Estado revise suas situações e os receba permanentemente - tornam-se solicitantes do refúgio e em seguida refugiados. Há um acirramento do conflito e a pessoa, na nova região, pode ficar tão vulnerável quanto estava em seu lugar de origem. Peter Nyers (2019) estuda o migrante irregular, aquele que atravessou a fronteira ou permanece em um local sem autorização legal do Estado anfitrião, como o refugiado. Para ele, “o migrante irregular é a exceção à norma: uma

\footnotetext{
2 Texto original: "Other foreigners such as migrants and immigrants may of course present a challenge to the identity or ethnic make-up of a community. Yet their transnational movement has been one of choice and they remain rooted in the 'normal' state-citizen relationship. The refugee, in contrast, has had no choice in leaving her country of origin. She has been forced outside the domestic political community of her state of origin and arrives at the borders of a host state requesting entry."
} 
identidade perturbadora entre a comunidade de cidadãos onde questões de pertença e identidade estão supostamente resolvidas" (Nyers, 2019, p. 33). Essa categoria é enquadrada em uma determinada legislação e política pública, cujo objetivo principal é proporcionar proteção.

O ACNUR está à frente da crise dos refugiados venezuelanos e, conforme pesquisa realizada pela Diretoria de Análise de Políticas Públicas da Fundação Getúlio Vargas (FGV-DAPP), pelo Observatório das Migrações Internacionais (OBMigra) e pela Universidade Federal de Roraima (UFRR), o estado de Roraima (entre 2016 e 2017) registrou crescimento e diversificação econômica durante o período de intensificação da chegada dos refugiados venezuelanos. A economia do estado cresceu mais rápido que a dos outros estados e o Produto Interno Bruto (PIB) teve aumento de 2,3\%, mais do que o crescimento médio de $1,4 \%$ dos outros estados brasileiros no mesmo período. Os dados demonstram que a economia continua crescendo e se desenvolvendo, beneficiando o País, e que a proteção aos refugiados não é apenas um gasto para o governo.

O ACNUR (2020) afirma que já foram criados 13 abrigos temporários sob sua supervisão nas cidades de Pacaraima e Boa Vista, em Roraima. O órgão também fornece ajuda e orientação legal nas chegadas e distribui água potável e kits de higiene para mulheres e crianças em áreas das fronteiras. Até dezembro de 2018, conforme a $4^{\mathrm{a}}$ edição do relatório Refúgio em Números, publicado pelo Comitê Nacional para os Refugiados - CONARE (2019), o Brasil recebeu 85.438 solicitações de reconhecimento da condição de refúgio da Venezuela. Destas, 61.681 foram recebidas apenas no ano de 2018 e 81\% foram apresentadas no estado de Roraima. Em 14 de junho de 2018, o CONARE decidiu reconhecer a situação de "grave e generalizada violação de direitos humanos" no país andino, fundamentado no inciso III do art. $1^{\circ}$ da Lei $n^{0} 9.474 / 97$, de modo que se simplifica o processo de solicitação de refúgio.

\section{A INTERNACIONALIZAÇÃO DOS DIREITOS HUMANOS E O ADVENTO DOS DIREITOS DOS REFUGIADOS}

A proteção internacional dos Direitos da Pessoa Humana é formada pelo Direito Internacional dos Direitos Humanos, o Direito Internacional Humanitário e o Direito Internacional dos Refugiados. Apesar de haver características compartilhadas, a coexistência dessas três realidades protetivas, no âmbito internacional, não é pacífica. Todavia, Trindade (2003) explica que, em essência, o objetivo desses três Direitos é o mesmo: a proteção do ser humano em seus aspectos mais fundamentais e vulneráveis e do modo mais efetivo possível.

O Direito Internacional dos Refugiados é uma especificidade dos Direitos Humanos que pretende ganhar forças e alcançar essas pessoas que são, talvez, entre os vulneráveis, os mais desprotegidos. Assim, parte-se da compreensão que considera a existência de um sistema único de proteção da pessoa humana dividido em três grandes vertentes. 
Após a Segunda Guerra Mundial, diante da atrocidade que foi vista naquele período, a comunidade internacional entendeu que seria importante viabilizar meios capazes de garantir a segurança humana e, consequentemente, assegurar sua sobrevivência. Dessa forma, depreende-se que os direitos humanos são garantias individuais que objetivam a proteção dos direitos mais essenciais do ser humano em face ou de outros seres humanos - uma vez que, por serem todos essencialmente iguais, um não pode influenciar na esfera individual alheia -, ou em face do Estado (JUBILUT, 2007).

A construção dos Direitos Humanos ${ }^{3}$ almejou a proteção do ser humano no que diz respeito à violação de direitos por parte do Estado, já que é no Estado que esses direitos são exercidos, é nele que o indivíduo exerce sua personalidade jurídica, como preceitua o artigo $6^{\circ}$ da Declaração Universal dos Direitos Humanos (1948): “[...] todos os indivíduos têm direito ao reconhecimento, em todos os lugares, da sua personalidade jurídica”. Somente no Estado podem ser realizadas essas garantias. É relevante considerar que o ser humano precede o Estado e adere a este por vontade própria, com o objetivo de promover proteção institucional a si. Por ser criação humana, não é possível a criatura sobrepor-se ao seu criador: o Estado deve ser instrumento dos homens e não o contrário.

Portanto, deve-se manter o ser humano como figura mais relevante possível em relação à construção estatal, o que se daria pela proteção humana originária dos direitos humanos. Estes devem ser resguardados em face da atividade do Estado. Hannah Arendt (2012, p. 395) expõe o que representou os Direitos Humanos para os indivíduos do Estado moderno:

\begin{abstract}
A Declaração dos Direitos Humanos, no fim do século XVIII, foi um marco decisivo na história. Significava que doravante o Homem, e não o comando de Deus nem os costumes da história, seria a fonte da Lei. Independente dos privilégios que a história havia concedido a certas camadas da sociedade ou a certas nações, a declaração era ao mesmo tempo mostra de que o homem se libertava de toda espécie de tutela e o prenúncio de que já havia atingido a maioridade.
\end{abstract}

Houve reconhecimento dos direitos humanos e, em seguida, sua positivação no ordenamento jurídico interno dos países. Posteriormente, esses direitos foram levados ao âmbito universal. Para Flávia Piovesan (2017, p. 351),

A internacionalização dos direitos humanos constitui, assim, um movimento extremamente recente na história, que surgiu a partir do pós-guerra, como respostas às atrocidades e aos horrores cometidos durante o nazismo. Apresentando o Estado como o grande violador de direitos humanos, a Era Hitler foi marcada pela lógica da destruição e da descartabilidade da pessoa humana, o que resultou no extermínio de

\footnotetext{
3 Existe uma diferença entre Direitos Humanos e Direitos Fundamentais. Estes são os direitos principais do ser humano positivados pelas ordens jurídicas dos Estados, internamente, e aqueles estão relacionados à liberdade e à igualdade que estão protegidas no plano internacional, ainda que não tenham respaldo em documentos internos. Utiliza-se para efeito deste estudo a expressão "direitos humanos", pois o assunto relacionado aos refugiados é, em essência, internacional.
} 
onze milhões de pessoas. O legado do nazismo foi condicionar a titularidade de direitos, ou seja, a condição de sujeito de direitos, à pertinência a determinada raça - a raça pura ariana.

No período de pós-Segunda Guerra Mundial, nasceu a Organizações das Nações Unidas (ONU), em 1945, que substituiu a Liga das Nações com o propósito de atuar na manutenção da segurança e da paz mundial e de desenvolver uma política internacional de aspecto universal e representativo entre os Estados, com caráter totalmente apolítico, humanitário e social. Jennifer Hyndman (2000, p. 3) esclarece, todavia, "que não há soluções humanitárias apolíticas capazes de lidar com deslocamentos humanos, tendo em vista que estes são eventos políticos”. Em razão disso, para a autora, o humanitarismo é um processo politizado que balanceia as necessidades dos refugiados e de outras pessoas deslocadas com os interesses dos Estados - isso fica mais claro quando se percebe que, entre os países sul-americanos, o Brasil é o que menos recebe refugiados venezuelanos.

Apesar disso, a ONU inaugura uma nova ordem internacional, fundada em princípios que modelam e dão novo significado ao conceito de soberania e que inclusive exercem funções constitucionais - como a limitação da discricionariedade dos Estados, obrigando-os a proteger os direitos humanos (DELGADO; GUEDES, 2017). É um organismo internacional que reafirma o movimento de internacionalização dos direitos humanos, pois, se a Segunda Guerra significou a ruptura com os direitos humanos, o Pós-Guerra deveria significar a sua reconstrução (PIOVESAN, 2017, p. 352).

No ano de 1948, foi elaborada a Declaração Universal dos Direitos do Homem, um marco para a internacionalização dos direitos humanos. A partir desse documento, direitos básicos dos seres humanos puderam fazer parte da ordem jurídica internacional, não restritos apenas aos ordenamentos jurídicos internos dos Estados. A comunidade internacional reconheceu a pessoa humana como parte direta da sociedade humana, naturalmente atuante como cidadão do seu país e igualmente cidadão do mundo, devido à proteção internacional que lhe é reconhecida.

A Declaração Universal dos Direitos Humanos tem como característica o universalismo, que garante os direitos a todas as pessoas, e a indivisibilidade, que protege todos os direitos. Flávia Piovesan (2010, p. 142) sintetiza o significado da Declaração Universal dos Direitos Humanos:

A Declaração Universal de 1948 objetiva delinear uma ordem pública mundial fundada no respeito à dignidade humana, ao consagrar valores básicos universais. Desde seu preâmbulo, é afirmada a dignidade inerente a toda pessoa humana, titular de direitos iguais e inalienáveis. Vale dizer, para a Declaração Universal a condição de pessoa é o requisito único e exclusivo para a titularidade de direitos. A universalidade dos direitos humanos traduz a absoluta ruptura com o legado nazista, que condicionava a titularidade de direitos à pertinência à determinada raça (a raça pura ariana). 
Esses mecanismos funcionavam e apresentavam um núcleo jurídico internacional atento ao indivíduo em tempos de paz. Para os problemas que envolvem pessoas na condição de refúgio, por outro lado, tem-se o Direito Internacional dos Refugiados. Este apresenta seu fundamento no conceito de humanitarismo e nos princípios básicos do Direito Internacional dos Direitos Humanos e tem como objetivo um ponto específico da proteção do indivíduo, que é protegê-lo da perseguição sofrida em função da raça, da religião, da nacionalidade, entre outros abusos. Os refugiados recebem proteção do Direito Internacional dos Direitos Humanos e também do Direito Internacional dos Refugiados, os quais trazem mais garantias e proteção para essas pessoas. Como esclarece Jubilut (2007, p. 61),

Tal fato é extremamente positivo, pois fortalece a proteção ao refugiado, uma vez que, ao mesmo tempo em que se assegura o refúgio, livrando-o de violações de direitos relativos ao seu status civil, ele traz em si a necessidade de resguardar também os demais direitos humanos, para, com isso, aumentar o nível de proteção dado à pessoa humana.

A Declaração e Programa de Ação de Viena (1993) classifica no artigo $5^{\circ}$ os direitos humanos como universais, indivisíveis, interdependentes e inter-relacionados. O direito de migrar e poder ser recebido com proteção é a essência dos direitos dos refugiados. As pessoas que estão nessa condição não devem somente ser recebidas, elas precisam de políticas públicas que lhes garantam recomeçar suas vidas no país escolhido para viver.

A partir da Convenção das Nações Unidas sobre o Estatuto dos Refugiados de 1951, a tutela aos refugiados se fortaleceu, já que o artigo $1^{\mathrm{o}}$ definiu o conceito de refugiado e apresentou 0 princípio da não devolução - non-refoulement -, que impedia os países de expulsarem os refugiados de volta para seus países de origem, onde havia perseguição e violência. Desde aquele momento, a Convenção é considerada o eixo fundador do Direito Internacional dos Refugiados (BARICHELLO; ARAUJO, 2014).

A Convenção de 1951, contudo, no que se refere ao conceito de refugiado, ainda revelava limitações temporais e geográficas que foram tornando o documento ineficaz. Devido a essas limitações, foi estabelecido, no ano de 1967, o Protocolo sobre o Estatuto dos Refugiados, que ampliou o alcance da definição desse termo. Barichello e Araujo (2014, p. 73) explicam que

O Protocolo buscou eliminar as limitações geográficas e temporais contidas na Convenção de 51, a qual estabelecia que somente seriam reconhecidos como refugiados aqueles que tivessem receio de serem perseguidos em consequência dos acontecimentos ocorridos antes de $1^{\circ}$ de janeiro de 1951.

Outro valoroso documento, de âmbito regional, que corrobora os direitos dos refugiados, é a Declaração de Cartagena sobre Refugiados (1984), que estabelece conexão entre as três correntes da proteção internacional - Direitos Humanos, Direito dos Refugiados e Direito Humanitário - e influencia a política migratória adotada pelo Brasil. Essa legislação nasceu dos encontros de 
representantes e especialistas de dez países latino-americanos na cidade de Cartagena das Índias, na Colômbia. O objetivo era debater a situação dos refugiados na América Latina. O Colóquio ampliou a definição do termo refugiado ao concluir, na terceira parte do documento, que havia "violação maciça dos direitos humanos”.

Também no âmbito regional, importa destacar a Declaração de San José sobre Refugiados e Pessoas Deslocadas (1994), que reconheceu a violação de direitos humanos como o motivo mais frequente para os deslocamentos humanos e para os pedidos de refúgio, concluindo que a proteção desses direitos é a melhor solução para prevenção dessas crises. O Brasil, desde os anos 1990, ratificou ou está em processo de ratificação da maioria dos tratados internacionais de direitos humanos, sendo estes norteadores dos princípios da Constituição de 1988 e responsáveis pela existência de uma efetivação jurídica da matéria. O País também coopera com a ONU e com a Organização de Estados Americanos (OEA) para a defesa dos direitos humanos.

\section{POLÍTICA MIGRATÓRIA BRASILEIRA}

A política migratória brasileira se baseia, essencialmente, na Constituição da República Federativa do Brasil (CRFB/88) e nas Leis $n^{0}$ 9.474, de 1997, e $n^{0} 13.445$, de 2017. É fundamental reconhecer que o Brasil, no âmbito externo, ratificou vários Tratados sobre direitos humanos, mas durante vinte e um anos (1964 - 1985) viveu sob uma ditadura militar que cerceava os direitos dos cidadãos. Sob essa perspectiva de "segurança", o estrangeiro era visto como nocivo ao País, pois o colocaria em risco. Este pode ser considerado um posicionamento, no mínimo, contraditório por parte do Governo.

A transição do período ditatorial para a reabertura democrática do Brasil foi feita pelo próprio comando do regime militar, sob o slogan "lenta, gradual e segura", o que ocasionou uma falta de debate mais amplo sobre seu significado e sobre o enfrentamento das violações aos direitos humanos ocorridas nos anos de chumbo (BAGGIO, 2019). Com o fim da Ditadura Militar e a promulgação da Constituição de 1988, nasce a expectativa de tutela absoluta aos direitos humanos e a tentativa de mudar a imagem do País, que estava arranhada devido a denúncias, no exterior, de violações de direitos humanos. A criação da Lei no ${ }^{0}$ 9.474/97, que rege os mecanismos do refúgio no Brasil, é um exemplo da boa vontade legislativa que o País apresentou, direcionada à população refugiada.

É fundamental elucidar, no entanto, que a Constituição de 1988, a qual deveria ser um símbolo de repactuação social e democrática do País, confrontava seus princípios constitucionais com o legado autoritário que a Lei no 6.815/80 (Estatuto do Estrangeiro) havia estabelecido nos anos de opressão. O tema é complexo, mas durante trinta e sete anos a referida lei (fundamentada no paradigma da segurança nacional e da proteção do mercado de trabalho interno) produziu efeitos no 
ordenamento jurídico brasileiro até, finalmente, ser revogada pela Lei $n^{0}$ 13.445/17 (Lei de Migração).

A Constituição de 1988 é influenciada pela Declaração de Cartagena e, já no art. $1^{\circ}$, aborda os fundamentos que constituem o Estado Democrático de Direito, como a dignidade da pessoa humana. $\mathrm{O}$ art. $3^{\mathrm{O}}$ apresenta os objetivos fundamentais do Brasil, dentre os quais estão o de "[...] construir uma sociedade livre, justa e solidária" e o de "[...] promover o bem de todos, sem preconceitos de origem, raça, sexo, cor, idade e quaisquer outras formas de discriminação". $\mathrm{O}$ art. $4^{0}$ evidencia a ideia de um país integrado com a comunidade internacional, colaborador do desenvolvimento das outras nações e do fortalecimento dos direitos humanos, pois,

No esforço de reconstrução dos direitos humanos do Pós-Guerra, há, de um lado, a emergência do Direito Internacional dos Direitos Humanos, e, de outro, a emergência da nova feição do Direito Constitucional ocidental, aberto a princípios e a valores, com ênfase no valor da dignidade humana. Por sua vez, no âmbito do Direito Constitucional ocidental, testemunha-se a elaboração de textos constitucionais abertos a princípios, dotados de elevada carga axiológica, com destaque ao valor da dignidade humana (PIOVESAN, 2017, p. 353 e 354).

O texto da CRFB/88 não aborda expressamente os refugiados, mas eles estão inseridos no princípio da dignidade da pessoa humana (art. $1^{\circ}$, inciso III, CRFB/88) e na prevalência dos direitos humanos (art. $4^{\circ}$, inciso II, CRFB/88). Além desses dispositivos, existe o artigo $5^{\circ}$ da CRFB/88, o qual assegura que "[...] todos são iguais perante a lei, sem distinção de qualquer natureza, garantindo-se aos brasileiros e aos estrangeiros residentes no País a inviolabilidade do direito à vida, à liberdade, à igualdade, à segurança e à propriedade”. Para Jubilut (2007, p. 181),

Com base nesses princípios, pode-se afirmar que os alicerces da concessão do refúgio, vertente dos direitos humanos e espécie do direito de asilo, são expressamente assegurados pela Constituição Federal de 1988, sendo ainda elevados à categoria de princípios de nossa ordem jurídica. Sendo assim, a Constituição Federal de 1988 estabelece, ainda que indiretamente, os fundamentos legais para a aplicação do instituto do refúgio pelo ordenamento jurídico brasileiro.

Além de obrigar o Brasil a cuidar dos direitos humanos e a respeitá-los, a concessão do refúgio seria uma forma de efetivação dos dispositivos constitucionais, de modo que os princípios estariam sendo cumpridos e a igualdade, assegurada, gerando segurança jurídica sobre o tema. É importante salientar que o refugiado, quando reconhecido pelo País, goza de igualdade perante os brasileiros natos e naturalizados, uma vez que é detentor dos direitos sociais preceituados pelo artigo $6^{\circ}$ da CRFB/88, mas não tem direito de votar nem de ser votado, o que proporciona uma complexa e necessária discussão sobre a cidadania desse grupo de pessoas.

O Brasil, em 1997, viabilizou uma lei específica para os refugiados: a Lei no 9.474, de 22 de julho, que estabeleceu os critérios para se conseguir o status de refugiado e determinou o procedimento para o devido reconhecimento desse status. A legislação representou de forma 
satisfatória os Tratados firmados pelo País alguns anos antes. A lei é, também, responsável pela criação do CONARE, órgão administrativo que trata do tema dos refugiados.

A Lei n ${ }^{0}$ 9.474/97 foi produzida a partir do Programa Nacional de Direitos Humanos de 1996 e elaborada pelo governo brasileiro em conjunto com o ACNUR. A referida legislação é conhecida como umas das mais avançadas do mundo e é pioneira na América Latina, "[...] sendo usada como parâmetro para inúmeros outros países, pois traz uma ampla abordagem de situações que caracterizam o status de refugiado" (PEREIRA, 2004, p. 36). Apesar de ser considerada importante em âmbito internacional, permanece aquém de legislações como a do México e a da Argentina, pois nesses países a legislação específica para os refugiados traz também a questão de gênero como fundamento de perseguição e concessão do refúgio.

No ano de 2017, foi aprovada no Brasil a Lei $n^{0}$ 13.445, que revogou o Estatuto do Estrangeiro - Lei no 6.815/80. A nova legislação, responsável por regulamentar as questões de migração, deveria representar um pleno avanço para a ordem constitucional tanto pelo processo de mobilização social - uma vez que sua inicialização contou com a participação da sociedade - quanto pela expectativa de superação da herança autoritária que detinha a antiga lei.

No entanto, a forma como se consolidou o processo legislativo e, acima de tudo, a fundamentação dos vetos do Presidente da República também presentes no decreto de regulamentação da nova lei comprovaram a permanência da lógica da segurança nacional, como explica Baggio (2019, p. 29), “deslindando as dificuldades de superação de nossa cultura autoritária e dificultando a consolidação da tão reivindicada condição da migração como um direito humano fundamental".

Os avanços implementados pelo novo marco legal são importantes e foram celebrados por muitos pesquisadores, movimentos e representantes da sociedade civil afeitos ao tema das migrações. Dentre as melhorias, destacaram-se a desburocratização do processo de regulação migratória, a institucionalização da política de vistos humanitários e a não criminalização dos indivíduos por razões migratórias. Contudo, tais medidas devem ser consideradas com cautela e criticidade, levando-se em conta o momento histórico e as inúmeras dificuldades que a legislação teve de superar em relação ao antigo processo político imposto ao Brasil.

Esse fato fez com que a CRFB/88, apesar dos seus inegáveis avanços na defesa dos direitos humanos, continuasse a reproduzir, sutilmente, a lógica autoritária contra os estrangeiros, porque a Lei $n^{\circ} 6.815 / 80$ continuava a produzir efeitos no ordenamento jurídico do País. No início do século XXI,

Em razão da migração de retorno, de novos fluxos migratórios que foram se organizando em direção ao país e da falta de harmonização entre o Estatuto do Estrangeiro e a $\mathrm{CF} / 88$, foi necessária uma intensa produção de normas relativas às questões de migrações, sobretudo por meio de instrumentos infra legais - como as resoluções de órgãos colegiados - o que não significou uma necessária articulação do tema em termos de elaboração de uma nova política nacional sobre migrações, ao 
contrário, foi tornando a aplicação dessas normativas cada vez mais complexas (CLARO, 2015, p. 121).

A nova realidade migratória que o Brasil vivia e as inúmeras legislações infralegais, que não conseguiam suprir a demanda dessa nova realidade, foram os combustíveis para que a sociedade exigisse uma nova legislação, mais adequada ao novo momento e mais ampla na defesa dos direitos humanos dos estrangeiros, para que se abandonasse totalmente a lógica estabelecida pela lei $\mathrm{n}^{\mathrm{O}}$ $6.815 / 80$.

Como a CRFB/884 não considera o imigrante cidadão brasileiro sob o viés político, porque o indivíduo nessa situação não pode votar nem ser votado, foi organizada a $1^{\text {a }}$ Conferência Nacional sobre Migrações e Refúgio (COMIGRAR) ${ }^{5}$, que levou ao Congresso brasileiro uma lista com solicitações a fim de que o legislativo pudesse legislar por uma norma atualizada e mais condizente com os princípios constitucionais. É importante evidenciar que a nova Lei de Migração não contemplou todas as reivindicações trazidas pelo COMIGRAR. A principal omissão foi a não previsão da criação de uma autoridade migratória civil que desvinculasse da competência da Polícia Federal a recepção e regularização do migrante, já que o art. 117 do Projeto de Lei (PL) 288/13, que previa a criação do órgão por influência do anteprojeto da comissão de especialista, foi retirado do texto final aprovado, por apresentar vício de iniciativa (BAGGIO, 2019).

Ainda que a lei não contemple todas as reivindicações, a denominação "Lei de Migração" é algo significativo e simbólico, pois demonstra a compreensão de que migrar é um direito humano, em oposição ao "Estatuto do Estrangeiro", que impunha aos "estrangeiros" um "estatuto" demasiadamente limitador. Além disso, os vetos, por parte do Presidente da República, antes da sua publicação - justificados pela ideologia de segurança nacional - deixam claro que o estrangeiro ainda não era bem-vindo no País:

Em detrimento da proteção dos direitos humanos das pessoas migrantes, dos povos indígenas e das populações tradicionais, o veto condena o texto original da Lei à lógica autoritária da legislação anterior, permitindo a primazia do fundamento securitário que se propunha a abandonar quando do início dos debates sobre a necessidade de um novo marco legal (BAGGIO, 2019, p. 54).

Entre importantes avanços e retrocessos permanentes, os ideais da política migratória brasileira vão sendo aplicados a quem aqui chega. Não obstante ser signatário de vários acordos para proteção dos direitos humanos dos refugiados e estrangeiros, o País internamente tem uma atuação

\footnotetext{
4 A CRFB/88 não igualou o imigrante ao cidadão brasileiro, pois é exigida a nacionalidade brasileira para o alistamento eleitoral - não sendo possível o voto para o imigrante - de acordo com o artigo 14, § $3^{\circ}$, inciso I. 5 A Conferência foi realizada entre os dias 30 de maio e $1^{\circ}$ de junho de 2014 na cidade de São Paulo e foi coordenada pelo Ministério da Justiça, por meio da Secretaria Nacional de Justiça/Departamento de Estrangeiros (DEEST), em parceria com o Ministério do Trabalho e Emprego e o Ministério das Relações Exteriores, com o apoio da Organização Internacional para as Migrações (OIM) e do Programa das Nações Unidas para o Desenvolvimento (PNUD).
} 
dúbia, uma vez que não consegue assegurar os avanços dos direitos humanos conquistados por essa população.

\section{CONARE E OS DESAFIOS ENFRENTADOS}

Por meio da lei nº 9.474/97, foi criado o CONARE, comitê do governo encarregado de revisar e decidir todas as solicitações de refúgio no Brasil. Ele também é a autoridade responsável por definir a política brasileira de refúgio, está ligado ao Ministério da Justiça e é constituído por representantes dos seguintes Ministérios: Justiça, Relações Exteriores, Trabalho e Emprego, Saúde, Educação, assim como por representantes da Polícia Federal e de organizações da sociedade civil dedicadas à assistência, integração local e proteção dos refugiados no Brasil. A Agência da ONU para Refugiados (ACNUR) e a Defensoria Pública da União têm um assento no CONARE com direito de voz, mas não de voto.

O procedimento para a solicitação e a concessão do refúgio no Brasil, resumidamente, acontece da seguinte forma: primeiro, solicita-se, nas fronteiras, a condição de refugiado à Polícia Federal; a análise do pedido é realizada pela Cáritas Arquidiocesanas; a decisão é proferida, em primeira instância, pelo CONARE, e dessa decisão, caso seja negado o reconhecimento do status de refugiado, inicia-se uma quarta fase, o recurso cabível da decisão negativa do CONARE para o Ministro da Justiça, que decidirá em último grau de recurso.

A atuação do comitê não se limita ao registro dos refugiados, uma vez que atua também na formulação de políticas impulsionadoras da integração ao País, como a Operação Acolhida. Esse programa, criado pelo Governo Federal, estrutura-se no ordenamento da fronteira (preparação da fronteira para receber os refugiados), no abrigo (para acomodação em abrigos com alimentação, educação, cuidados em saúde e proteção) e na interiorização (transporte dos refugiados para diferentes regiões do Brasil). A interiorização é a principal estratégia do governo brasileiro para promover a inclusão socioeconômica dos imigrantes venezuelanos, contribuindo também para que os serviços públicos no estado de Roraima não entrem em colapso. Segundo dados do Governo Federal (2020), desde abril de 2018 - início dos trabalhos - até janeiro de 2020, mais de 27,2 mil pessoas foram interiorizadas para 376 cidades, em 24 estados.

Desde o início de sua existência, no ano de 1998, o CONARE já realizou mais de 70 reuniões plenárias e mais de 13 reuniões extraordinárias; de acordo com a $4^{\mathrm{a}}$ edição do relatório Refúgio em Números, publicado pelo comitê (2019), o Brasil reconheceu, entre 2011 - 2018, 11.231 mil pessoas refugiadas. O órgão decidiu, em 2018, 13.083 processos. Destes, reconheceu elegibilidade a 777 , arquivou 2.165 e extinguiu 3.949 processos.

O país que mais apresenta solicitações de refúgio ao Brasil é a Venezuela, com 61.681 mil, representando $77 \%$ do total do número de solicitações de reconhecimento de refugiado. Os estados 
brasileiros onde mais há solicitações do reconhecimento da condição de refúgio são Roraima (com 50.770 mil - 63\% do total), Amazonas (10.500 mil - 13\% do total), São Paulo (9.977 mil - 12\% do total) e Paraná (1.408 mil - 2\% do total). Apesar de existirem programas para levar os refugiados a outros lugares, com intuito de facilitar suas vidas, ao chegarem nas cidades eles continuam enfrentando constantes problemas para serem incluídos na sociedade.

Simões et al. (2017, p. 21-48), no Relatório sobre o Perfil Sociodemográfico e Laboral da Imigração no Brasil, evidenciou que somente 38,9\% dos venezuelanos tiveram acesso aos serviços de saúde, 10,4\% aos serviços educacionais e 2,2\% aos serviços de assistência social. Sobre os que têm certificado de ensino superior, a pesquisa evidencia que 90,48\% não conseguem a revalidação dos diplomas, fator que impacta negativamente o sucesso de conseguirem emprego nas suas áreas de formação. O percentual de refugiados que frequentou ou frequenta curso de português no País é de 53,66\%, um índice baixo, porque mais de 48\% dos entrevistados falam outro idioma além daqueles perguntados (português, francês, inglês, espanhol e árabe). Além disso, salienta-se que 7,1\% estão sem documentação no Brasil, 22,8\% possuem carteira de trabalho e 29\%, Cadastro de Pessoa Física. Patriota (2017, p. 174, tradução nossa ${ }^{6}$ ) defende:

O exercício da responsabilidade em relação aos migrantes, refugiados e apátridas não deve se limitar a oferecer reassentamento. Deveria também envolver esforços visando garantir sua total integração nas sociedades anfitriãs. Isso inclui proporcionar condições de vida decentes, proteger os migrantes e refugiados da discriminação e deportação arbitrária e combater o discurso xenofóbico.

Para haver uma plenitude da dignidade humana e uma possível integração desses refugiados no Brasil, é necessário mais do que oferecer abrigos, alimentação e operações de acolhimentos. Os refugiados que chegam ao País querem recomeçar suas vidas e construir um futuro com perspectivas reais, tanto para eles, quanto para os filhos, e para isso é necessário que haja documentos de identificação para todo(a)s, que seja permitida sua entrada formal no mercado de trabalho7, que consigam estudar e dominar o idioma e que estejam participando da sociedade de forma segura, sem preconceitos e violências, portanto, não sendo permitido visualizar a humanidade como sujeito de Direito a partir da ótica do Estado; impõe-se reconhecer os limites do Estado a partir da ótica da humanidade (TRINDADE; ROBLES, 2003).

6 Texto original: "The exercise of responsibility towards migrants, refugees and stateless persons should not be limited to offering resettlement. It should also entail efforts aimed at ensuring their full integration into host societies. This includes providing decent living conditions, protecting migrants and refugees from discrimination and arbitrary deportation, and combating xenophobic discourse."

7 No caso das mulheres, observa-se que os programas que as inserem ao mercado de trabalho geralmente reforçam os estereótipos de feminilidade e o lócus de atuação restrito ao espaço da casa e da família. Dessa forma, oferecer oficinas de costuras e de gastronomia como reintegração dessas mulheres ao mercado de trabalho deve ser analisado com cuidado e senso crítico. 


\section{CONSIDERAÇÕES FINAIS}

Apesar de os fluxos migratórios sempre existirem na história da humanidade, somente a partir do século XX se discute a proteção daqueles que foram forçados a fugir em busca de refúgio. Mesmo com a internacionalização dos direitos humanos e a ampliação do conceito de refugiado realizada pelos documentos de direitos humanos e, consequentemente, com a ratificação da maioria dos Estados, a efetivação desses direitos é sensível à vontade política dos países. Neles se exercem as proteções internacionais, por isso é importante a ratificação de documentos internacionais, fundamentais para a elaboração de leis nacionais e de políticas públicas mais eficazes.

No Brasil, a política migratória revelou, sem dúvidas, muitos avanços. Apesar dos erros e da inoperância administrativa, o País mostrou-se assertivo ao assinar os acordos internacionais para proteção dos refugiados. Internamente, no período democrático, houve a criação de um sistema jurídico migratório audacioso, porque garantiu a pluralidade de direitos aos refugiados, mas ainda com resquícios da ideologia da segurança nacional, timidamente mascarada por políticas públicas pouco eficientes.

O Brasil é o país sul-americano que menos recebe venezuelanos na condição de refúgio e que tem grande dificuldade de integrá-los à sociedade. A Lei $n^{0}$ 9.474/97 revela uma proposta muito válida, que foi ao encontro da Declaração de Cartagena de 1984. Já a Lei no 13.445/17 (Lei de Migração), não obstante ter considerado a migração como um direito humano, relativizou essa proteção ao ser aprovada com omissões importantes, cujas justificativas se fundamentam na velha ideologia da segurança nacional.

*Artigo recebido em 30 de março de 2020, aprovado em 28 de maio de 2020.

\section{REFERÊNCIAS}

Agência da ONU para Refugiados (ACNUR). 5 dados sobre refugiados que você precisa conhecer. Disponível em: https://www.acnur.org/portugues/2019/04/09/5-dados-sobrerefugiados-que-voce-precisa-conhecer/. Acesso em: 07 maio 2020.

ARENDT, Hannah. Origens do Totalitarismo. São Paulo: Companhia das Letras, 2012.

BAGGIO, Roberta Camineiro. O processo de construção do novo marco legal migratório no Brasil: entre a ideologia da segurança nacional e o direito humano a migrar.: Entre a Ideologia da Segurança Nacional e o Direito Humano a Migrar. Revista Direitos Fundamentais \& Democracia, Curitiba, v. 24, n. 3, p. 27-59, 12 dez. 2019. Disponível em: https://revistaeletronicardfd.unibrasil.com.br/index.php/rdfd/article/view/1299. Acesso em: 01 maio 2020. 
BARICHELLO, Stefania Eugenia; ARAUJO, Luiz Ernani Bonesso de. Aspectos históricos da evolução e do reconhecimento internacional do status de refugiado. Universitas Relações Internacionais, Brasília, v. 12, n. 2, p. 63-76, jul. 2014. Disponível em: https://www.researchgate.net/publication/272019669 Aspectos historicos da evolucao e do reconhecimento internacional do status de refugiado. Acesso em: 09 maio 2020.

BAUMAN, Zygmunt. Estranhos à nossa porta. Rio de Janeiro: Zahar, 2017.

BRASIL. Constituição (1988). Constituição da República Federativa do Brasil de 1988. Brasília, Disponível em:

http://www.planalto.gov.br/ccivil 03/Constituicao/Constituicao.htm. Acesso em: 14 mar. 2020.

- Define mecanismos para a implementação do Estatuto dos Refugiados de 1951, e $\overline{\text { determina }}$ outras providências. Lei no 9.474/97. Brasília, Disponível em: http://www.planalto.gov.br/ccivil 03/Leis/L9474.htm. Acesso em: 14 mar. 2020.

. Institui a Lei de Migração. Lei no 13.445/17. Brasília, Disponível em: http://www.planalto.gov.br/ccivil 03/ ato2015-2018/2017/lei/L13445.htm. Acesso em: 14 mar. 2020.

CLARO, Carolina de Abreu Batista. As Migrações Internacionais no Brasil sob uma Perspectiva Jurídica: análise da legislação brasileira sobre estrangeiros entre os séculos XIX e XXI. Cadernos OBMIGRA. Brasília, v. 1, n. 1, p. 119-210, 2015.

Governo Federal. Operação Acolhida. Disponível em: https://www.gov.br/acolhida/historico/. Acesso em: 11 maio 2020.

HADDAD, Emma. The Refugee in International Society: between sovereigns. Oxford: Cambridge University Press, 2008.

HYNDMAN, Jennifer. Managing displacement: refugees and the politics of humanitarianism. Minnesota: University of Minnesota Press, 2000.

IOM, International Organization for Migration -. World Migration Report 2020. Geneva: 2020. Disponível em: https://publications.iom.int/es/system/files/pdf/wmr 2020.pdf. Acesso em: 07 maio 2020.

JUBILUT, Liliana Lyra. O Direito Internacional dos Refugiados e sua aplicação no orçamento jurídico brasileiro. São Paulo: Método, 2007. 240 p.

O Procedimento de Concessão de Refúgio no Brasil. 2010.

. Refugee Law and Protection in Brazil: a model in South America? Journal of Refugee Studies. Oxford, v. 19, n. 1, p. 22-44, 2006.

JUSTIÇA, Secretaria Nacional de. Refúgio em Números. 4. ed. Brasília: SNJ, 2019.

MOREIRA, Julia Bertino. Política em relação aos refugiados no Brasil (1947-2010). 2012. 377 f. Tese (Doutorado) - Curso de Ciência Política, Universidade Estadual de Campinas, Campinas, 2012.

NYERS, Peter (ed.). States of Refuge: keywords for critical refugee studies. Canada: Mcmaster University, 2019. Disponível em: https://www.academia.edu/41586780/States of Refuge Keywords for Critical Refugee Studi es. Acesso em: 10 maio 2020. 
OLIVEIRA, Renata Peixoto de. Velhos fundamentos, novas estratégias?: petróleo, democracia e a política externa de Hugo Chávez (1999-2010). Petróleo, Democracia e a Política Externa de Hugo Chávez (1999-2010). 2011. 182 f. Tese (Doutorado) - Curso de Ciência Política, Universidade Federal de Minas Gerais, Belo Horizonte, 2011.

PATRIOTA, Antônio de Aguiar. State Responsibility in the protection of migrants, refugees and stateless persons. Boletim da Sociedade Brasileira de Direito Internacional: Boletim 100 anos. Belo Horizonte, v. 103. p. 165-175, 2017. Disponível em: https://drive.google.com/file/d/1U8Jym4r61ghZelJj HgNoJM-okPJltMd/view. Acesso em: 08 maio 2020.

PEREIRA, Gustavo Oliveira de Lima. Direitos Humanos e hospitalidade: a proteção internacional para apátridas e refugiados. Atlas, 08/2014.

PIOVESAN, Flávia. Direitos Humanos e o Direito Constitucional internacional. São Paulo: Saraiva, 2010.

. Flávia. Temas de Direitos Humanos. São Paulo: Saraiva, 7. ed., 2014.

RODRIGUES, Francilene. Migração transfronteiriça na Venezuela. Dossiê Migração, São Paulo, v. 20, n. 57, ago. 2006. Disponível em: http://www.scielo.br/scielo.php?pid=So10340142006000200015\&script=sci arttext\&tlng=pt. Acesso em: 23 mar. 2020.

SARMENTO, G. S. Diagnóstico sobre las migraciones caribeñas hacia Venezuela. Buenos Aires: PLACMI-OIM, 2000.

SAYAD, Abdelmalek. O que é um imigrante? Peuples Méditerranéens, Lyon, v. 7, p. 3-23, abr. 1979. Disponível em: https://www.academia.edu/23966139/Abdelmalek Sayad A imigrac a o ou os paradoxos da alteridade. Acesso em: 12 maio 2020.

SIMÕES, Gustavo da Frota et al (Org.). Perfil Sociodemográfico e Laboral da imigração venezuelana no Brasil. Curitiba: Editora CRV, 2017. Disponível em: https://editoracrv.com.br/produtos/detalhes/32684-detalhes. Acesso em: 14 set. 2019.

SOUZA, Ayrton Ribeiro de; SILVEIRA, Marina de Campos Pinheiro da. O fluxo migratório de venezuelanos para o Brasil (2014-2018). Cadernos PROLAM/USP, [s.l.], v. 17, n. 32, p.114132, 28 ago. 2018. Universidade de São Paulo Sistema Integrado de Bibliotecas - SIBIUSP. http://dx.doi.org/10.11606/issn.1676-6288.prolam.2018.144270.

TRINDADE, Antônio Augusto Cançado. Tratado de Direito Internacional dos Direitos Humanos. Porto Alegre: Sergio Antônio Fabris Editor, 2003.

TRINDADE, Antônio Augusto Cançado; ROBLES, Manuel E. Ventura. El Futuro de la Corte Interamericana de Derechos Humanos. San José: Corte Interamericana de Derechos Humanos, 2003. 321 p. Disponível em: http://www.corteidh.or.cr/sitios/libros/todos/docs/futurocorteidh.pdf. Acesso em: 04 maio 2020.

United Nations High Commissioner for Refugees. A Economia de Roraima e o Fluxo Venezuelano: Evidências e Subsídios para Políticas Públicas. Disponível em: https://www.acnur.org/portugues/wp-content/uploads/2020/03/A-economia-de-Roraima-e-ofluxo-venezuelano-2pg-Summary-Port.pdf. Acesso em: 04 maio 2020. 